Anuario Latinoamericano Ciencias Políticas

y Relaciones Internacionales

vol. 5, 2017

pp. $127-155$

\section{El desarrollo de los estudios sobre administración y políticas públicas en la Argentina}

\section{The development of studies in the field of administration and public policy in Argentina}

\author{
Nelson Dionel Cardozo* \\ UNIVERSIDAD ARGENTINA DE LA EMPRESA \\ UNIVERSIDAD DE BUENOS AIRES, ARGENTINA \\ $\triangle$ nelson.cardozo@gmail.com
}

\section{RESUMEN}

Este artículo analiza la constitución del campo de la administración y las políticas públicas, centrándose en su enseñanza en la Argentina. Se estudian los sistemas de grado y posgrado, como así también las distintas etapas históricas y la concepción que se ha tenido sobre los temas y problemas que se fueron desarrollando. Se hace mención a los representantes más destacados que ha tenido el país en esta materia y la constitución del prestigio del área.

PALABRAS CLAVE: Argentina, administración pública, Estado, políticas públicas, ciencia política.

\begin{abstract}
This article analyzes the constitution of the field of administration and public policies, focusing on its teaching in Argentina. The degree and postgraduate systems are studied, as well as the different historical stages and concepts about the issues and problems that were developed. Mention is made of the most outstanding representatives that the country has had in this area and the establishment of prestige of the area.
\end{abstract}

KEYWORDS: Argentina, public administration, State, public policy, political science.

* Profesor e investigador de la Universidad Argentina de la Empresa (UADE) y de la Universidad de Buenos Aires (UBA). Se ha especializado en temas de historia y enseñanza de la ciencia política y en políticas públicas comparadas. 
Dossier

América Latina:

desarrollo y balance de la ciencia política

\section{Pensar los estudios disciplinares}

Durante los últimos años ha crecido el interés por los estudios disciplinares dentro de la ciencia política y las relaciones internacionales en América Latina. En una primera etapa centrados en tratar de describir principalmente las experiencias nacionales y posteriormente focalizándose en la historia intelectual de algunos destacados especialistas como así también en profundizar algunas áreas temáticas en particular. De trabajos muy exploratorios y básicos se ha pasado a investigaciones más profundas y con argumentaciones teóricas y metodológicas más adecuadas para abordar la historia de una disciplina. También se ha creado grupos de trabajo especiales dentro de algunas asociaciones nacionales de ciencia política como en la Asociación Latinoamericana de Ciencia Política (ALACIP) (Bulcourf et al. 2014; Bulcourf et al. 2015).

En este trabajo nos focalizaremos en el campo de confluencia de saberes que representan los estudios sobre el Estado, la administración y las políticas públicas, aunque destacando que ha sido la ciencia política la disciplina específica que más se ha interesado en estos problemas durante las últimas décadas en la Argentina. Por esta razón, admitimos que el concepto de "campo" sea posiblemente el más adecuado para referirnos a los interrogantes que se hacen presentes, aunque no descartamos la idea se analizarlos como un área específica dentro de la ciencia política (Bourdieu 2003; Bulcourf, Vázquez 2004; Cardozo, Bulcourf 2016). Nos focalizaremos ante todo en el proceso de creación e institucionalización de las carreras de grado y posgrado vinculadas principalmente por el campo, analizando su evolución histórica y su vinculación con otros aspectos del proceso social. Haremos una pequeña cartografía de los principales actores y grupos de investigación que han desarrollado sus actividades en universidades y centros de investigación, como así también mencionaremos algunas obras que se produjeron durante estos períodos, más que nada con un carácter ilustrativo.

Uno de los temas que queremos comenzar a plantear en este trabajo es el complejo proceso de construcción del prestigio dentro del campo, resaltando un enfoque crítico frente a los criterios de validación dentro de la comunidad científica, principalmente dentro de las humanidades y ciencias sociales.

Orienta el artículo los planteos surgidos a partir de la declaración del Manifiesto de Popayán que suscribieran en 2014 un conjunto de especialistas en temas de historia y desarrollo de la ciencia política. Resaltamos en este sentido que dentro de la constitución de un campo del saber no solo prevalecen las cuestiones estrictamente vinculadas a la construcción de conocimiento científico válido, sino también relaciones de poder que condicionan y orientan a la propia comunidad, la que no debe ser estudiada por fuera de los procesos culturales, sociales, económicos y políticos de la cual son parte. Es así que resaltamos también el carácter "político" que posee indagar sobre la historia de la ciencia política y toda disciplina científica, vínculos que muchas veces no quedan manifiestos en una primera instancia. Es por esta razón que nuestra aproximación se reconoce a sí misma como parcial y transitoria, sin por ello perder su validez. 
Las ciencias sociales, como en realidad sucede en todos los ámbitos del conocimiento, son plurales y diversas, cruzadas por intereses, cosmovisiones y aspectos más ideológicos y políticos. Abordaremos ahora casualmente un ámbito muy especial por la propia cercanía a su objeto de estudio y a la necesidad expresa de servir como un elemento a la propia toma de decisiones.

\section{La constitución del campo del la administración y las políticas públicas en la Argentina}

La administración pública es un concepto que engloba diversas ideas vinculadas entre sí. Por un lado, la función de administración pública que es una esfera tradicionalmente relegada por los estudios politológicos por estar escindida de la toma de decisiones de última instancia y sus instituciones (ejecutivos y legislativos). En segundo término, se suele aludir a la idea de administración pública como el conjunto de organismos públicos a veces llamado sector público, gobierno, burocracia o agencias públicas que son los cuerpos encargados de la ejecución rutinaria de la implementación de las políticas públicas. En tercer término, se refiere al campo del conocimiento que se desarrolló durante la posguerra entendido como área interdisciplinaria o rama de la ciencia política que se dedica a generar conocimiento sobre los procesos de la acción pública, su implementación y sus técnicas de evaluación (Bulcourf, Vázquez 2004). Esta última visión surge en occidente con los trabajos de Weber y Wilson, pero es durante la segunda posguerra que se constituye en un campo autónomo con teorías propias, investigadores, centros de enseñanza e investigación y una comunidad que nos permite hablar de un "campo" de la administración pública.

En occidente, la generación de conocimientos sobre la mejor forma de administrar la polis ha sido una preocupación que se remonta a la antigüedad clásica. Sin embargo, en los escritos de Platón y Aristóteles no aparecía claramente delimitada la escisión entre política y administración, sino que ésta se va constituyendo con la modernidad y el liberalismo. Hegel, en su obra la Filosofía del Derecho (1821), caracteriza a la burocracia como la clase universal que representaba el interés general del Estado. Así mismo, la crítica a la sociedad capitalista de Marx y Lenin describe a la administración pública como supeditada a las relaciones de poder infraestructural, razón por la cual persiste la idea de abolir administración pública y el propio Estado pasando a la sociedad socialista.

Hacia las primeras décadas del siglo XX, encontramos la reflexión con mayor profundidad en la cual podemos rastrear el origen de los estudios sobre la administración pública, los escritos de Max Weber sobre la burocracia. ${ }^{1}$ Allí,

1 Nos referimos fundamentalmente a Economía y sociedad. Esbozo de sociología comprensi$v a$, la obra más relevante del sociólogo alemán que fue editada de manera póstuma por su esposa Marianne Weber entre los años 1921 y 1922, donde se encuentra en el capítulo "Sociología de la
El desarrollo de los estudios sobre administración y políticas públicas en la Argentina

Nelson Dionel Cardozo 
Dossier América Latina: desarrollo y balance de la ciencia política el sociólogo alemán empieza a plantearse cuál es la mejor forma de administrar el Estado capitalista moderno. Su hipótesis central es que hay un proceso de racionalización mediante el cálculo matemático, donde la acción teleológica caracteriza las sociedades modernas.

Del lado de la empresa capitalista va surgiendo el estudio sobre la mejora de la productividad que se plasma en el nacimiento de las ciencias de la administración a comienzos del siglo pasado. Esto sucede de la mano los escritos del ingeniero mecánico Frederick Taylor, considerado el fundador de la moderna teoría general de la administración. El enfoque típico de la escuela de la administración científica es el énfasis en las tareas. El nombre administración científica se debe al intento de aplicar los métodos de la ciencia a los problemas de la administración, con el fin de alcanzar elevada eficiencia industrial. Los principales métodos científicos aplicables a los problemas de la administración son la observación y la medición.

Sin embargo, la constitución de la administración pública como área se va a dar como rama de la ciencia política, tras la crisis del Estado Liberal clásico después de la Gran Depresión y posteriormente con el Estado de Bienestar, lo cual marca un nuevo rol del Estado, razón por la cual son necesarias nuevas capacidades técnicas y políticas para poder planificar, implementar y evaluar políticas públicas. Entre los primeros que manifiestan su preocupación por el nuevo enfoque se encuentra Harold Laswell quien reclamaba la reorientación de la ciencia política hacia las políticas públicas. En la década del 50, Laswell y otros investigadores respondieron con un conductismo de segunda generación al que denominaron "ciencias de las políticas públicas" (policy sciences), poniendo un énfasis mayor sobre las cuestiones de política, intentando que en la atención de los problemas y sus soluciones no se perdiera el análisis científico. En un estudio editado en 1951, Harold Laswell parte de la preocupación de cómo utilizar los recursos intelectuales con la "más sabia economía". En esa dirección sostiene que se ha desarrollado una mayor conciencia en el sentido de que el proceso de la política requiere de estudios con derecho propio, fundamentalmente con la esperanza de aumentar la racionalidad de las decisiones. La orientación hacia las políticas (policy orientation) tiene un doble proceso, por una parte se ocupa del "proceso de las políticas", es decir de la formación y ejecución de las políticas utilizando los métodos de las ciencias sociales y de la psicología. Pero, además el "proceso de las políticas" se ocupa de las necesidades de inteligencia de este proceso con el objetivo de mejorar el contenido concreto de la información y de las interpretaciones disponibles para los creadores de la política; por consiguiente rebasa las fronteras de las ciencias sociales y la psicología. Este enfoque de las políticas públicas se centraba en la planificación como razón de ser del estudio sistemático en el hecho de realizar una buena programación de las políticas. En esta línea de argumentación, fue fundamental el rol que tuvo la planificación

Dominación" la construcción teórica acerca de la administración pública y la burocracia; que ha sido resumida y condensada en otras ediciones posteriormente. 
como elemento central por parte de los Estados nacionales en la segunda posguerra, en lo que se conoció como el Estado Keynesiano de Bienestar (EKB). En una escisión analítica más profunda, en un primer momento, la faceta keynesiana consistió en el rol de Estado como planificador de la actividad económica y agente del crecimiento, a partir una respuesta a las crisis del capitalismo clásico. Esto es lo que se conoce como las políticas económicas anticíclicas. Vale decir que este rol del Estado no tuvo una sistematización teórica hasta que John Maynard Keynes publicó en 1936 su Teoría general de la ocupación, el interés y el dinero, la cual es probablemente el libro que más influyó en la discusión económica de los países occidentales entre las décadas del 30 y del 50. Sin embargo, las primeras respuestas a la crisis que dio el gobierno norteamericano con el New Deal de Roosevelt carecieron de este marco teórico, dado que el mismo llegó años después. A su vez, la faceta de Estado de Bienestar, en los países centrales, y los Estados Benefactores o populistas (en América Latina) de la segunda posguerra, fueron los que se centraron en las concesiones del capital hacia el trabajo que redundaron en mejoras de las condiciones de vida de los ciudadanos de los países capitalistas con la finalidad de ampliar el margen de ciudadanía. Vislumbrado en la Alemania de Bismarck con el surgimiento de las instituciones del seguro social, durante la segunda posguerra el enfrentamiento ideológico capitalismo-comunismo, oriente-occidente, hizo preciso que se diera un marco de legitimidad e igualdad social al sistema capitalista.

El EKB, por consiguiente, requirió una creciente intervención del Estado que, a su vez, precisó incrementar su capacidad de respuesta a las demandas que estimulaba. El crecimiento de las "policy sciences", bajo esta perspectiva, fue fundamental para el desarrollo de este nuevo tipo de Estado. Ello es así, dado que todo lo mencionado más arriba, tanto en la arista de intervención macroeconómica y Estado empresario, como en las nuevas funciones como garante del bienestar, requirió la planificación de políticas públicas y burocracias capaces de implementarlas. Los ejemplos empíricos de lo mencionado fue la faraónica empresa de reconstrucción europea que encaró el "Plan Marshall", y en América Latina, los proyectos industrialistas de Vargas y Perón (y más tarde el desarrollismo de Kubitschek de Oliveira y Frondizi) que representaron una ampliación de las fronteras de la política pública como elemento transformador de la sociedad, asentada en el pilar de la organización centralizada por parte del Estado.

\section{Aspectos institucionales del proceso de construcción del campo en el país}

Intentaremos en los apartados siguientes trazar un derrotero desde una perspectiva histórica, en un primer término, para luego realizar una mapeo del desarrollo institucional de la enseñanza en el área de administración y políticas públicas en la Argentina. Esto parte, por un lado, de estudios disciplinares
El desarrollo de los estudios sobre administración y políticas públicas en la Argentina

Nelson Dionel Cardozo 
Dossier América Latina: desarrollo y balance de la ciencia política previos que entroncan el nacimiento del área referida como parte de la especialización de la ciencia política (Bulcourf 2008) e indagaciones más generales sobre este sub-área disciplinar (Bulcourf, Dufour, Cardozo 2013), que tienen la premisa que uno de los ejes para estudiar el desarrollo de un campo del saber son las instituciones de enseñanza, es decir los centros de producción y reproducción de la comunidad del conocimiento.

De hecho, uno de los aspectos que menciona Oszlak (1997) en relación al caso argentino es que hay una desvinculación entre la implementación de las políticas públicas y la investigación en este campo disciplinar. La falta de articulación entre estas instancias ha tenido consecuencias negativas para la consolidación de esta área de estudio. No obstante ello, podemos esgrimir que hubo diferentes fases del proceso de la conformación de las políticas públicas como campo. Vemos que el crecimiento sostenido de los posgrados en esta área se realiza desde la democratización en adelante, consolidándose desde finales de los años 90. Por su parte, luego de la creación de la primera carrera de ciencia política y administración pública de la Universidad de Cuyo, en 1952, hay un hiato hasta finales los años 90 en donde comienzan a crearse las carreras de grado en la administración pública.

\section{El inicio de la enseñanza del campo de las políticas públicas y la democratización en la Argentina}

Luego de entrar en el año 1916, dentro de lo que Huntington denominará "Primera Ola Democratizadora", entre los años 1930 y 1983, Argentina experimentó, una "contraola" con el golpe de Estado y la instauración de un gobierno autoritario que marcará el llamado "péndulo cívico-militar" argentino, donde asistiremos a más de medio siglo sin poder consolidar una democracia. Tras el autodenominado Proceso de Reorganización Nacional (1976-1983), el último gobierno autoritario de nuestro país, la derrota en la Guerra de Malvinas precipitó la transición democrática "por colapso" que inauguró el actual período democrático. El cambio de régimen planteó problemáticas a nivel de la estructura interna del Estado e inauguró el debate sobre la formación institucionalizada para capacitar un nuevo cuerpo de funcionarios. Con esta idea surgida de la propia presidencia de "refundar" la administración pública se da un nuevo impulso al Instituto Nacional de la Administración Pública (INAP), creado en el año 1973, durante la tercera presidencia de Perón, siendo este organismo junto con la Secretaría de la Función Pública que tuvo su génesis en el pasado gobierno autoritario, la punta de lanza de esta modernización de la burocracia rioplatense.

A nivel institucional, en Argentina la administración pública es eminentemente un área de especialización dentro de las ciencias sociales que se realiza con posterioridad a los estudios de grado. El desarrollo de la administración pública como campo disciplinar tiene su origen dentro del posgrado antes que 
del grado. El nacimiento de carreras de grado con la denominación administración pública es una experiencia más tardía, encontrándose relacionado con la creación de nuevas universidades y a cambios vinculados a la visión de la disciplina. Según Andrieu y Asencio (2006), el surgimiento de los posgrados con orientación en Políticas Públicas tiene su inicio a partir del año 1985 con la creación de la Maestría en Políticas Públicas del Instituto Torcuato Di Tella (después Universidad Torcuato Di Tella) con el apoyo del Banco Interamericano de Desarrollo. En la resolución de la Comisión Nacional de Evaluación y Acreditación Universitaria (CONEAU) 382/04 que acredita el programa se vuelca que dicho programa se dicta con fecha de inicio el año 1985, como una orientación (que ahora se presenta como carrera) del Programa de Posgrado en Economía y Políticas Públicas del Instituto Di Tella, mediante convenio de cooperación técnica con el Banco Interamericano de Desarrollo, para el otorgamiento de becas a graduados latinoamericanos. Oportunamente, esta maestría fue acreditada en 1995 por la Comisión de Acreditación de Posgrados (CAP) del Ministerio de Educación con categoría "B” y, en 1998 por la CONEAU con categoría “A” (Res CONEAU, no 813/99).

Siguiendo la política gubernamental de modernización del sector público, el hito más relevante en la constitución de la administración pública como campo de estudio es la creación de la maestría en Administración Pública de la Universidad de Buenos Aires. El gobierno del presidente Raúl Alfonsín en una clara política de profesionalizar la función pública y generar conocimiento sobre el Estado, dio impulso al nacimiento de dicho programa con el apoyo del Instituto Nacional de la Administración Pública, la Secretaría de la Función Pública, y el CONICET que aportó becas.

Como menciona el portal del programa "esta iniciativa se fundamentó en la necesidad de dar respuesta a la creciente diversificación de la actividad estatal, a la correspondiente complejización de su aparato administrativo, sus políticas, sus formas organizativas y sus mecanismos de decisión, mediante la formación de recursos humanos de alta capacitación para el desarrollo de la investigación y de especialistas en la materia”. La tensión entre la formación para la gestión o la academia se hizo evidente desde el comienzo. Si bien se menciona la orientación a la investigación, por otro lado se hace énfasis en formación hacia la gestión pública, toda vez que pretende incluir „una adecuada combinación de enfoques disciplinarios, sin soslayar el carácter interdependiente y multifacético de los fenómenos estudiados desde cada uno de ellos tendiendo a que los contenidos y orientaciones de las enseñanzas mejoren la capacidad interpretativa y predictiva de analistas administrativos, formuladores de políticas públicas y administradores". No obstante ello, es menester destacar que todos los tramos de maestría son de orientación académica, en virtud que por exigencia de la CONEAU se establece que para la acreditación de estos programas se incluye la realización de un trabajo, proyecto, obra o tesis de carácter individual, bajo la supervisión de un director, que culmina con la evaluación por un jurado, el cual incluye al menos un miembro externo a la
El desarrollo de los estudios sobre administración y políticas públicas en la Argentina

Nelson Dionel Cardozo 
Dossier América Latina: desarrollo y balance de la ciencia política institución. El trabajo final, proyecto, obra o tesis debe demostrar destreza en el manejo conceptual y metodológico correspondiente al estado actual del conocimiento en la o las disciplinas del caso. Conduce al otorgamiento de un título académico de Magíster con especificación precisa de una disciplina o de un área interdisciplinaria. En lo atinente a la estructura curricular el programa está previsto ser completado en dos años y la formación se centra en 5 núcleos temáticos: Administración Pública - 4 materias; Jurídico - 3 materias; Análisis Organizacional - 3 materias; Investigación - 4 asignaturas; que se complementan con una pasantía y 10 créditos de materias optativas que son rotativas.

\section{Los posgrados en administración y políticas públicas}

Durante la presidencia de Alfonsín se dio un gran impulso al carácter fundacional del gobierno a partir de diversas iniciativas tales como la creación del Consejo para la Consolidación de la Democracia -una instancia de producción académica que debatía sobre las reformas institucionales necesarias para mejorar la calidad del régimen político, la cual tuvo impacto directo en la creación de la carrera de Ciencia Política de la Universidad de Buenos Aires en el año 1985.

Con la llegada de Carlos Menem al poder (1989-1999) se va a dar lo que se considera uno de los procesos de reforma estructural hacia una economía de mercado de los más profundos en la región en un contexto democrático, siendo comparable únicamente con el caso mexicano, caracterizado por una impronta decisionista y una celeridad inusitada. Estos vertiginosos cambios, que se conocen como la "reforma del Estado", implicaron dos aristas bien diferenciadas. Por un lado, una rearticulación en la relación entre el Estado y la sociedad, en el sentido de la atribución de competencias entre una y otra, donde se intentó abandonar el esquema de matriz estadocéntrica basado en un modelo keynesiano del Estado empresario y regulador, para dar lugar a la liberalización de las relaciones económicas en una matriz mercadocéntrica. Así esta primera dimensión implicó la privatización de empresas públicas -transferencia de propiedad de compañías públicas a manos de capitales privados-; desregulación de la economía -eliminación de marcos regulatorios que restringen el accionar de los agentes económicos-; desmonomopolización -permitir la entrada de otras empresas oferentes que compitan con los prestadores gubernamentales-; y finalmente la descentralización -delegar en niveles provinciales y municipales tareas y responsabilidades que se encontraban en la órbita federal/nacional-. La segunda dimensión tuvo que ver con la reestructuración del aparato estatal, que consistió en un proceso de dos acciones: la reorganización de las agencias gubernamentales, intentando reducir el número de dependencias públicas, y finalmente la reducción de la plantilla de personal -mediante la transferencia de personal a compañías privatizadas, jubilaciones, despidos, retiros voluntarios, relocalización en los gobiernos subnacionales, y cesantías. 
Durante los años de reforma del Estado (1989-1994) no se crearon programas de posgrado en el área; sino que vemos que a partir del período de la Segunda Generación de Reformas, hacia finales de los años 90 es que surgen nuevos programas de formación en el tramo de maestría a partir del año 1998, con la creación de la Maestría en Políticas Públicas de la Universidad de San Andrés (UdeSA). A partir de este momento vamos a ir asistiendo a proceso de expansión de estos cursos en todo el país, abarcando una amplia cobertura geográfica. De la indagación de la base de datos de la CONEAU y los diversos portales de las universidades, hemos podido rastrear 16 maestrías en administración o gestión públicas que se dictan en universidades. De ellos, solamente el de la Universidad de Buenos Aires ha sido acreditado como A "Excelente" por la CONEAU, mientras que el de la Universidad San Andrés ha obtenido la calificación An (nuevo).

\begin{tabular}{|c|c|c|c|c|}
\hline Denominación & Institución & $\begin{array}{l}\text { Año de } \\
\text { creación }\end{array}$ & Cat. & Res. \\
\hline $\begin{array}{l}\text { Maestría en Políticas } \\
\text { Públicas }\end{array}$ & $\begin{array}{l}\text { Universidad Torcuato } \\
\text { Di Tella }\end{array}$ & 1985 & No Solicitó & Res382-04 \\
\hline $\begin{array}{l}\text { Maestría en } \\
\text { Administración } \\
\text { Pública }\end{array}$ & $\begin{array}{l}\text { Universidad de Buenos } \\
\text { Aires }\end{array}$ & 1986 & A & Res357-00 \\
\hline $\begin{array}{l}\text { Maestría en } \\
\text { Administración } \\
\text { Pública Prov. } \\
\text { y Municipal }\end{array}$ & $\begin{array}{l}\text { Universidad Nacional } \\
\text { de Córdoba }\end{array}$ & 1989 & B & Res415-09 \\
\hline $\begin{array}{l}\text { Maestría en } \\
\text { Administración } \\
\text { y Políticas Públicas }\end{array}$ & $\begin{array}{l}\text { Universidad de San } \\
\text { Andrés }\end{array}$ & 1998 & An & Res356-00 \\
\hline $\begin{array}{l}\text { Maestría en } \\
\text { Administración } \\
\text { Pública } \\
\end{array}$ & $\begin{array}{l}\text { Universidad Nacional } \\
\text { del Litoral }\end{array}$ & 1998 & $\mathrm{~B}$ & Res587-09 \\
\hline $\begin{array}{l}\text { Maestría en Política } \\
\text { y Gestión Pública }\end{array}$ & $\begin{array}{l}\text { Universidad } \\
\text { Empresarial Siglo } 21\end{array}$ & 1999 & Proyecto & Res266-99 \\
\hline $\begin{array}{l}\text { Maestría en Gestión } \\
\text { Pública }\end{array}$ & $\begin{array}{l}\text { Universidad Nacional } \\
\text { de Misiones }\end{array}$ & 2000 & Proyecto & Res696-00 \\
\hline $\begin{array}{l}\text { Maestría en } \\
\text { Políticas Públicas } \\
\text { y Gerenciamiento } \\
\text { del Desarrollo } \\
\text { (O/C Epyg Unsam - } \\
\text { U. Georgetown, Usa) }\end{array}$ & $\begin{array}{l}\text { Universidad Nacional } \\
\text { de General San Martín }\end{array}$ & 2000 & B & Res573-05 \\
\hline $\begin{array}{l}\text { Maestría en Políticas } \\
\text { Públicas y Gobierno }\end{array}$ & $\begin{array}{l}\text { Universidad Nacional } \\
\text { de Lanús }\end{array}$ & 2000 & No Solicitó & Res985-05 \\
\hline
\end{tabular}

El desarrollo de los estudios sobre administración y políticas públicas en la Argentina

Nelson Dionel Cardozo

\section{Cuadro 1.}

Maestrías en Administración y Políticas Públicas en Argentina 


\begin{tabular}{|c|c|c|c|c|c|}
\hline \multirow{2}{*}{$\begin{array}{r}\text { Dossier } \\
\text { América Latina: } \\
\text { desarrollo y balance } \\
\text { de la ciencia política }\end{array}$} & $\begin{array}{l}\text { Maestría en Ciencias } \\
\text { del Estado }\end{array}$ & $\begin{array}{l}\text { Universidad del } \\
\text { CEMA }\end{array}$ & 2001 & No solicitó & Res245-04 \\
\hline & $\begin{array}{l}\text { Maestría en Gerencia } \\
\text { Pública }\end{array}$ & $\begin{array}{l}\text { Universidad Nacional } \\
\text { de la Patagonia San } \\
\text { Juan Bosco }\end{array}$ & 2004 & No Solicitó & Res726-04 \\
\hline & $\begin{array}{l}\text { Maestría } \\
\text { en Administración } \\
\text { Pública }\end{array}$ & $\begin{array}{l}\text { Universidad del } \\
\text { Salvador }\end{array}$ & 2004 & No solicitó & No acreditada \\
\hline & $\begin{array}{l}\text { Maestría en Gestión } \\
\text { Pública }\end{array}$ & $\begin{array}{l}\text { Universidad Católica } \\
\text { de Córdoba }\end{array}$ & 2004 & No solicitó & Acreditada \\
\hline & $\begin{array}{l}\text { Maestría en Gestión } \\
\text { Pública }\end{array}$ & $\begin{array}{l}\text { Universidad Nacional } \\
\text { de Rosario }\end{array}$ & 2005 & Proyecto & Res482-06 \\
\hline & $\begin{array}{l}\text { Maestría } \\
\text { en Administración } \\
\text { Pública }\end{array}$ & $\begin{array}{l}\text { Universidad Nacional } \\
\text { de La Rioja }\end{array}$ & 2008 & No solicitó & Res049-07 \\
\hline $\begin{array}{r}\text { Cuadro } 1 . \\
\text {. }\end{array}$ & $\begin{array}{l}\text { Maestría } \\
\text { en Evaluación de } \\
\text { Políticas Públicas }\end{array}$ & $\begin{array}{l}\text { Universidad Nacional } \\
\text { de Entre Ríos }\end{array}$ & 2012 & $\begin{array}{l}\text { En } \\
\text { evaluación }\end{array}$ & Acreditada \\
\hline
\end{tabular}

Fuente: Elaboración propia con base en los datos de la CONEAU.

De la observación de la evolución de la creación de los únicos posgrados con nivel de maestría, según lo relevado hasta el año 1998, fueron la maestría en Políticas Públicas de la Universidad Torcuato Di Tella y la maestría en Administración Pública de la Universidad de Buenos Aires. Luego, el número comienza a ascender hasta llegar al número de 16 en el año 2009, para mantenerse en esa cantidad para el año 2016.

Ahora bien, es menester señalar que el área de formación de posgrado en administración pública es mucho más amplia que la referida a los programas de administración pública o políticas públicas. Si tomamos este criterio estamos dejando a uno de los cinco posgrados en ciencias sociales de la Argentina acreditado como A: la maestría en Políticas Sociales de la Universidad de Buenos Aires. Esto se debe a que no incluimos dentro de las maestrías en Administración Pública a ningún programa con orientación en políticas públicas sectoriales. A raíz de ello podemos ordenar las maestrías de acuerdo al criterio que toman Andrieu y Asencio (2006) para dividir temáticamente los posgrados en Administración Pública a partir de la clasificación que hace el INAP en su red de posgrados. Allí podemos encontrar las siguientes áreas temáticas: Gestión Pública; Jurídica; Auditoría y Control; Economía, Finanzas y Estadísticas; Políticas Sociales; Justicia y Seguridad; Desarrollo Económico; Defensa; y Salud. En el siguiente gráfico se condensa el número de programas de posgrados incluidos en la red de posgrados del INAP: 


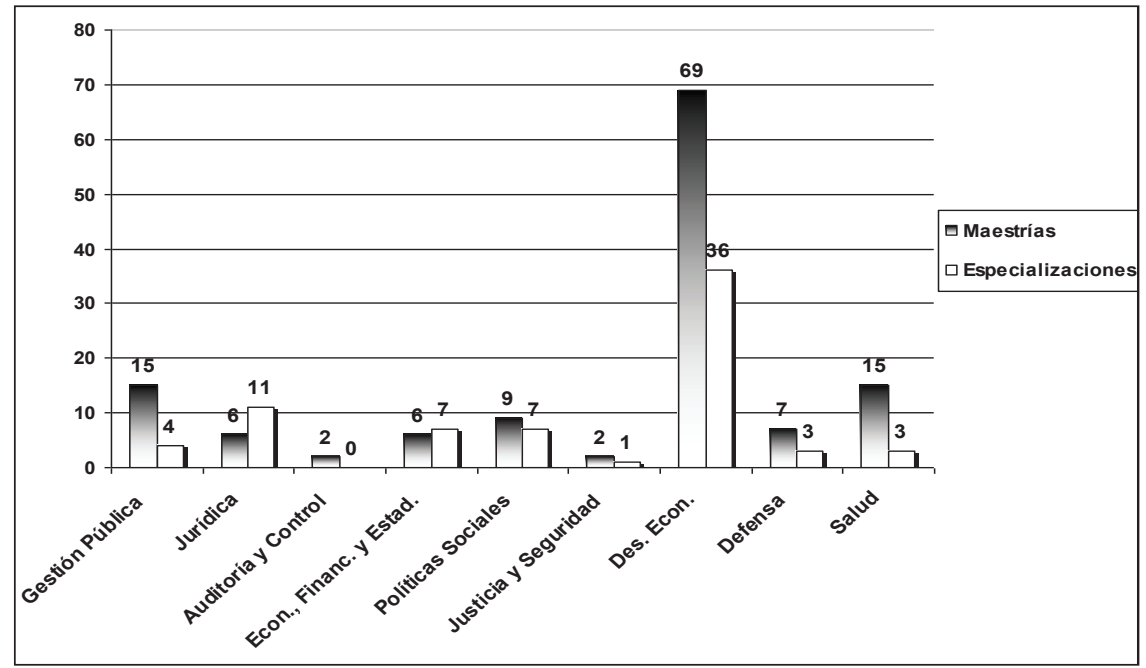

Fuente: Elaboración propia con base en datos del Instituto Nacional de la Administración Pública, [https://www.argentina.gob.ar/inap].

De la primera observación del cuadro surge que el área más importante del conjunto de posgrados es Desarrollo Económico. Ello es así porque incluye una amplia variedad de temática en donde están incluidos las ingenieras, las ciencias agropecuarias, biología, veterinaria, biotecnología, alimentación, por lo que podría decirse que todo tipo de políticas sectoriales que no puede ser englobada en las anteriores queda contenido en esta categoría. Luego vemos que el segundo grupo de gestión pública, en donde están comprendidas la mayoría de las maestrías mencionadas en el cuadro anterior. También llama la atención las 11 especializaciones del área jurídica, lo cual es explicable por la tradición de esta disciplina, de corte profesionalista, motivo por el cual es de esperarse la profusión de trayectos de especialización en temas específicos de la práctica jurídica. Autón (2001) menciona, que "los contenidos de los programas de posgrados en administración pública generalmente se encuentran orientados o bien a temas de finanzas públicas o hacia un análisis sociológico de Estado y Sociedad, tratando de recoger las últimas teorías, sin embargo carecen de visión de gestión o management cotidiano de las políticas públicas, esto no es solo responsabilidad del sector académico, sino fundamentalmente del Estado que no ha precisado sus demandas en la materia" (Autón 2001: 5). Esta dimensión es resaltada por todos los textos de la materia: la desvinculación en gestión y el ámbito académico.

Finalmente, vemos que la instancia que se encuentra en una etapa más embrionaria es la del doctorado en donde encontramos solamente dos experiencias: el Instituto de Investigación y Formación en Administración Pública
El desarrollo de los estudios sobre administración y políticas públicas en la Argentina

Nelson Dionel Cardozo

Grafico 1.

Red de posgrados del INAP por área temática 
Dossier América Latina: desarrollo y balance de la ciencia política

(IIFAP), dependiente de la Universidad Nacional de Córdoba (UNC), puso en marcha en octubre de 2010 el primer Doctorado en Administración y Política Pública del país, contando con un ciclo de 14 cursos de seminarios y luego un ciclo de la tesis. El Primer Ciclo, de seminarios de doctorado, corresponde a la realización, por parte de los aspirantes, de cursos y/o seminarios -desarrollados en el Doctorado o en otras instituciones nacionales o extranjerasrelacionados con el abordaje de la problemática del anteproyecto o plan de tesis respectivo. El Segundo Ciclo es la Elaboración del Trabajo de Tesis Doctoral, que se corresponde al desarrollo, presentación y aprobación de un Plan de Tesis Doctoral y a la realización de los trabajos correspondientes por parte del doctorando. Este Ciclo esta orientado por un Director del Trabajo de Tesis y un co-director, en el caso de que ello resultare necesario. Este programa adopta la modalidad de un doctorado flexible, en virtud que el candidato puede ingresar en el primero o el segundo ciclo, teniendo en cuenta la formación $\mathrm{y}$ antecedentes de los postulantes.

\begin{tabular}{ll}
\hline \multicolumn{1}{c}{ Teoría Política } & \multicolumn{1}{c}{$\begin{array}{c}\text { Políticas Públicas en el campo } \\
\text { de la Población }\end{array}$} \\
\hline Teoría de la Adm. y la Política Pública & Políticas de Inclusión Social y Bienestar \\
\hline Hacia una Antropología del Estado & Mundo del Trabajo y Política Laboral \\
\hline Sociedad, Cultura y Comunicación & Política Pública en el campo de los DD HH \\
\hline Teoría del Desarrollo & $\begin{array}{l}\text { Planificación y Evaluación de Políticas } \\
\text { Sociales }\end{array}$ \\
\hline La Política Económica en transformación & Políticas de Comunicación Institucional \\
\hline Política y Gestión del Territorio & Sociología Política \\
\hline
\end{tabular}

Fuente: Elaboración propia.

Por otro lado, el Doctorado en Administración Pública en la Universidad Nacional de Litoral, actualmente bajo la dirección de Miguel Asencio, se propone "generar académicos de rango superior para la actividad docente de grado y posgrado, que a su vez sean aptos en la formación de recursos de alta calidad para la docencia y la transmisión de conocimientos, así como estudiosos destinados a producir, reproducir y aumentar el conocimiento existente a través de la investigación y la formación de recursos humanos para la investigación". Se estructura bajo una secuencia de tres ciclos integrativos: a) Ciclo de Créditos de Optimización Académica, b) Ciclo Metodológico y de Suficiencia en Investigación y c) Ciclo de Tesis. El primero procura suministrar un ámbito de consideración, análisis y debate científico de los conocimientos más recientes de avanzada o "de frontera"; el segundo apuesta a la maximización 
de la aptitud de los aspirantes para lograr una exitosa elaboración de tesis y el tercero, suministrar herramientas para poder alcanzar contribuciones originales que impone la normatividad argentina en vigencia, en la producción del conocimiento científico. Si se piensa en un poseedor previo de maestría con desempeño regular de cursado y tesis, su lapso completo de estudios al arribar al doctorado se ubica entre los cinco o seis años: después de 3 (tres) semestres, es decir 18 meses, que concluyen los dos primeros ciclos presenciales más el Subciclo de Formulación del Proyecto de Tesis, cuando aspirante está listo para iniciar el proceso fundamental de Elaboración de su Tesis Doctoral, el cual puede tener una extensión variable en años, dependiendo del tipo de tareas a desarrollar y dentro de los límites temporales fijados por las normas reglamentarias de la UNL.

\section{La enseñanza de grado en administración y políticas públicas}

Como se mencionó en la introducción a este trabajo, el proceso de constitución de un Estado de Bienestar en su versión latinoamericana implicó ampliar el límite de los conocimientos para la gestión pública. Vinculado al proyecto de modernización del sector público y siguiendo la impronta refundacional de la sociedad que tuvo el primer peronismo (1946-1955) podemos encontrar el antecedente a la formación de grado en administración pública. La primera carrera de grado bajo esta denominación comenzó a desarrollarse en la Universidad Nacional de Cuyo en el año 1951, al año siguiente de fusionar el programa en la creación de la carrera de ciencias políticas con un fuerte contenido orientado hacia la gestión pública. Tres años antes, a partir de los requerimientos emanados de la nueva Constitución de 1949, se hace obligatorio la enseñanza de contenidos políticos y de identidad nacional en todos los estudios universitarios en la Argentina. Esta casa es la primera en reformar sus planes de estudio y creando un Departamento de Estudios Políticos encargado de impartir cursos especializados y la publicación de una revista periódica; esto generó la "demanda" de instrumentar posteriormente una carrera de grado afín creándose la licenciatura en Ciencias Políticas, hoy licenciatura en Ciencia Política y Administración Pública. En sus comienzos los contenidos curriculares estaban orientados a la formación de funcionarios públicos con altos conocimientos de derecho público, historia y filosofía. Cabe destacar que desde sus comienzos tuvieron relevancia los estudios de pensamiento social latinoamericano bajo la conducción de Carlos Zuleta Álvarez. Posteriormente, al crearse la Universidad Nacional de San Juan a partir de la sede de la de Cuyo en esa provincia, también se continuó con la carrera de ciencia política con una fuerte orientación hacia las políticas de desarrollo, aun hoy vigente.

Como menciona Guardamagna, la finalidad que tenía la carrera de ciencia política y administración pública era la formación de un estamento dirigente de la
El desarrollo de los estudios sobre administración y políticas públicas en la Argentina

Nelson Dionel Cardozo 
Dossier

América Latina: desarrollo y balance de la ciencia política

vida política, dentro la concepción de Arturo Enrique Sampay. ${ }^{2}$ Bajo esta línea de argumentación, "retoma una definición de Estado, un Estado que debe jugar un papel sumamente importante que claramente no es el del abstencionismo y por ello la Alta Burocracia como parte de la clase política a la cual Weber hace referencia, deberá poseer cualidades especiales. En este sentido dirá que para conducir el país hacia la realización de los objetivos establecidos por la Constitución reformada de 1949 será menester formar un estamento dirigente que incluya a los burócratas de ese Estado gestor del bien común que instaura la Constitución" (Guardamagna 2008: 6). Vemos que estaba claramente orientada dentro de lo que podemos llamar hoy en día capacitación para la función pública, y no como la creación de un campo disciplinar tendiente a generar investigación empírica en la temática. Si bien no recurre a la idea estamental tradicional de reproducción de la burocracia como capa social, tampoco busca una vinculación entre investigación y planificación de políticas públicas como en los planteos de Lasswell, sino que se asocia a un doble proceso de formación política de la clase dirigente y la conformación de una burocracia capacitada para la implementación de las políticas públicas. Sin embargo, como podemos observar, fue una experiencia aislada, ya que quedó presa de las discontinuidades políticas y quiebres institucionales que acontecieron en nuestro país por 50 años, lo que impidió el desarrollo en el grado de la administración pública en lo que respecta a este nivel. Un hecho muy importante es que durante el Proceso de Reorganización Nacional se va a cambiar la denominación de la carrera a Administración Pública y Ciencia Política, vaciando el currículum de contenidos politológicos y orientándose hacia el derecho administrativo. Para ilustrar lo dicho precedentemente, se muestran en el siguiente cuadro los sucesivos cambios de nombre de la carrera de Ciencia Política y Administración Pública de la Universidad Nacional de Cuyo.

\begin{tabular}{ll}
\hline \multicolumn{1}{c}{ Plan Año } & \multicolumn{1}{c}{ Denominación } \\
\hline 1952 & Ciencias Políticas \\
\hline 1961 & Ciencias Políticas y Sociales \\
\hline $1968 / 1970$ & $\begin{array}{l}\text { Ciencias Políticas y Sociales con dos especialidades: Sociología } \\
\text { y Ciencias Políticas y Administración Pública }\end{array}$ \\
\hline 1976 & Administración Pública y Ciencias Políticas \\
\hline 1985 & Ciencias Políticas y Administración Pública \\
\hline $1994 / 1996$ & Ciencia Política y Administración Pública \\
\hline
\end{tabular}

Fuente: Elaboración propia con datos proporcionados por la Universidad Nacional de Cuyo.

\footnotetext{
2 Arturo Enrique Sampay (1911-1977) fue un jurista, constitucionalista y docente argentino, conocido como el ideólogo de la Constitución Argentina de 1949 y padre del constitucionalismo social en la Argentina. De ideas radicales en un inicio, desarrolló luego un pensamiento socialcristiano, adhiriendo al peronismo a partir de la década de 1940, con una visión crítica al constitucionalismo liberal.
} 
Allende esta singular experiencia que se desarrolló durante el peronismo, vamos a encontrar en la década de los 70 que se va a crear la licenciatura en Administración Pública en la Universidad de El Salvador, bajo la dirección de Oscar Oszlak, que solamente va a contar con dos promociones, según refiere su exdirector. Pero tras el proceso de democratización van a comenzar a crearse a partir de la segunda mitad de los años 90 carreras de grado en las nuevas universidades del Conurbano y, en el año 2009, comenzó a dictarse la primera carrera de Administración Pública en una universidad privada en la UADE, seguida en el año 2014 por la UMET. Así se puede avizorar lo dicho en el siguiente cuadro:

\begin{tabular}{llccc}
\hline \multicolumn{1}{c}{ Denominación } & Universidad & $\begin{array}{c}\text { Años de } \\
\text { Duración }\end{array}$ & $\begin{array}{c}\text { Año de } \\
\text { Creación }\end{array}$ & Ubicación \\
\hline $\begin{array}{l}\text { Licenciatura en Ciencia Política } \\
\text { y Administración Pública }\end{array}$ & UNCU & 5 & 1952 & Mendoza \\
\hline $\begin{array}{l}\text { Licenciatura en Administración } \\
\text { Pública }\end{array}$ & UNGS & 5 & 1993 & San Miguel \\
\hline $\begin{array}{l}\text { Licenciatura en Administración } \\
\text { Pública }\end{array}$ & UNSAM & 5 & 1998 & CABA/ GBA \\
\hline $\begin{array}{l}\text { Licenciatura en Administración } \\
\text { Pública }\end{array}$ & UNTREF & 4 & 2005 & Caseros \\
\hline $\begin{array}{l}\text { Licenciatura en Administración } \\
\text { Pública }\end{array}$ & UAER & 4 & 2006 & Paraná \\
\hline $\begin{array}{l}\text { Licenciatura en Administración } \\
\text { Pública }\end{array}$ & UNCOMA & 4 & 2006 & Viedma \\
\hline $\begin{array}{l}\text { Licenciatura en Política } \\
\text { y Administración Pública }\end{array}$ & UADE & 4 & 2008 & CABA \\
\hline \begin{tabular}{l} 
Licenciatura en Políticas Públicas \\
\hline
\end{tabular} & UMET & 4 & 2015 & CABA \\
\hline
\end{tabular}

Fuente: Elaboración propia con base en la Guía del Estudiante de EUDEBA.

En el cuadro anterior vemos que encontramos en el país 8 ciclos de licenciatura con la denominación "Administración Pública", la mayoría de las cuales se encuentran en las universidades públicas, con excepción de dictada en la Universidad Argentina de la Empresa (UADE). Sin embargo, de la consulta realizada con la base en el portal "Becas y Empleos", surgen 14 tramos de licenciatura, en virtud que se contabilizan las licenciaturas en Administración y Contador Público con orientación en Administración Pública de la Universidad del Centro de la Provincia de Buenos Aires, y la Licenciatura en Administración y Contabilidad del Sector Publico, orientado en Administraciones Marítimas del instituto Universitario de Seguridad Marítima de la Prefectura Naval Argentina. Así mismo se incluyen algunas licenciaturas en Ciencia Política con Orientación en Administración Pública.
El desarrollo de los estudios sobre administración y políticas públicas en la Argentina

Nelson Dionel Cardozo

\section{Cuadro 4.}

Carreras de grado con la denominación "Administración Pública" al año 2017 
Dossier América Latina: desarrollo y balance de la ciencia política
Otro aspecto interesante de destacar es la ubicación de las carreras. Lo que podemos señalar a primera vista es que se encuentran mayormente ubicadas en Buenos Aires (Capital y Área Metropolitana) y en las capitales de las provincias (Viedma, Mendoza y Paraná), de lo cual puede inferirse que el fundamento de la creación se vincula con la orientación en la participación de los gobiernos provinciales y nacionales. Así mismo vemos que tres de las universidades del Conurbano (Universidad Nacional de Tres de Febrero, Universidad Nacional de General Sarmiento y Universidad Nacional de General San Martín) incluyeron en sus programas de grado las carreras de Administración Pública.

El perfil de las nuevas carreras creadas en las tres universidades del Conurbano tiene una clara orientación hacia la gestión. Para afirmar esto tomamos lo dicho por sus docentes en un trabajo de análisis de la licenciatura en Administración Pública de la Universidad de General Sarmiento, en donde sostienen que el plan de estudios "buscó constituirse en un lugar particular, con una fuerte inserción en su zona de influencia, para dar respuestas concretas, a través de su trabajo, a las problemáticas de la región" (Agoff et al. 2003: 3). Por su parte, la Universidad Nacional de Tres de Febrero menciona en su portal que busca la formación de profesionales con conocimientos y habilidades para conducir sectores operativos de la administración pública (nacional, provincial, municipal), representar a los gobiernos en gestiones administrativas y analizar, diseñar y evaluar políticas administrativas estatales.

El Plan de Estudios de la carrera Licenciatura en Administración y Políticas Públicas de la Universidad de General San Martín se propone brindar una sólida formación básica en el campo de las ciencias sociales; ofrecer una sólida formación específica para el análisis de la administración gubernamental y de las políticas públicas; proporcionar al Estado argentino graduados universitarios con una sólida formación académico-profesional orientada a la administración de organizaciones gubernamentales y del funcionamiento estatal en distintos niveles jurisdiccionales, así como en el análisis e implementación de políticas públicas; promover el desarrollo de la capacidad de analizar e intervenir activa y creativamente en los procesos de toma de decisiones en el ámbito público.

Uno de los aspecto más llamativos de esta nueva fase es que en la última década han surgido dos programas de grado en universidades privadas con perfiles y orientaciones más diversificadas. Así las cosas, vemos que el trayecto formativo de la UMET -el primero con la denominación "Políticas Públicas", propone que los licenciados estarán capacitados para trabajar en la gestión especializada de organizaciones públicas, privadas, del sector del trabajo, del tercer sector y de entidades deportivas; contribuir a la creación de oportunidades de desarrollo y consolidación dentro de las organizaciones; diseñar y gerenciar proyectos y programas relacionados con su área de especialización; identificar y formular indicadores de gestión en coherencia con la gestión integral de la organización; comprender las necesidades y expectativas 
de las personas y las tendencias en desarrollo y gestión de las organizaciones; asesorar a altos mandos de organizaciones públicas, sociales y privadas, nacionales e internacionales; asesorar en el ámbito legislativo en materia de gestión social y de las organizaciones; formar parte y conducir equipos inter y multidisciplinarios de investigación en el área de su formación. La Universidad Argentina de la Empresa (UADE) tiene un denominado "Programa Conjunto" en donde adiciona materias a la Licenciatura en Gobierno y Relaciones Internacionales, de clara matriz politológica, otorgando un segundo título de licenciado en Política y Administración Pública que entre su perfil de egresado no resalta con mucho énfasis la especificidad más allá del campo de la ciencia política, y apunta también al perfil que conjuga la vinculación entre lo público y lo privado.

\section{La constitución del campo desde el período democrático}

Uno de los momentos centrales para la consolidación de los estudios sobre el Estado y las políticas públicas lo constituyó la creación del Centro de Estudios de Estado y Sociedad (CEDES) por parte de Oscar Oszlak, Eduardo Borneo, Guillermo O'Donnell y Marcelo Cavarozzi, originariamente como un desprendimiento del Centro de Investigación en Políticas Públicas (CIAP) que pertenecía al Instituto Di Tella. Esto sucedió paradójicamente en los albores de la cruenta dictadura militar que se instaurará en la Argentina a partir de 1976. La gran mayoría de los integrantes de la flamante institución había realizado sus estudios de posgrado en el exterior, lo que les permitió establecer un diálogo fecundo con la producción académica de los países centrales y también lazos institucionales y personales con centros de investigación destacados. De esta forma, no se trató solamente de un centro de aglutinamiento de académicos, sino también un espacio fértil para la producción teórica, la investigación empírica y la posterior difusión de sus productos. En el ámbito concreto de la teoría del Estado y su vinculación con el análisis de políticas públicas se destacaron principalmente Oscar Oszlak y Guillermo O'Donnell los que elaboraron lo que se denominó el enfoque "histórico estructural", una de las producciones más originales de las ciencias sociales argentinas. Esta visión pretendía, ante todo, poder analizar las relaciones entre el Estado " $y$ " la sociedad originadas en la particularidad de la historia latinoamericana y sus casos nacionales; es en este sentido que se construyó también como una visión crítica de la producción de los ámbitos académicos de los países centrales, pero siempre manteniendo un diálogo fecundo y constructivo con esta producción. Las críticas a las teorías del desarrollo y la modernización, por un lado, la producción neomarxista, por el otro, y una relectura a la obra de Max Weber dieron lugar a esta original forma de analizar las complejas relaciones sociales y políticas de los países
El desarrollo de los estudios sobre administración y políticas públicas en la Argentina

Nelson Dionel Cardozo 
Dossier

América Latina:

desarrollo y balance de la ciencia política de la región, algo que los autores mencionados venían analizando desde sus ya mencionadas estadías de posgrado en el exterior.

En un primer momento la publicación en 1972 de Modernización y autoritarismo por parte de Guillermo O'Donnell abrió una puerta importante al reconocimiento de la ciencia política argentina y, sobre todo, al planteo de una nueva y original forma de analizar las particularidades de la región. O'Donnell modifica la visión tradicional que sostenía la vinculación directa entre el desarrollo socioeconómico y la instauración de un régimen político democrático. Analizando los casos latinoamericanos, observa con claridad que esta hipótesis no tiene un correlato en los países con mayor desarrollo en la región, sino todo lo contrario. La pluralización política en estas situaciones derivó en regímenes de corte autoritario. Aparece aquí una primera aproximación a estas realidades con el concepto de régimen burocrático-autoritario que permitiría un posterior desarrollo. Ya dentro del CEDES esta concepción dará lugar a dos trabajos centrales, por un lado, el documento Apuntes para una teoría del Estado y, posteriormente, una de las obras centrales de la disciplina en la región, El Estado burocrático-autoritario (Bulcourf 2015; Cardozo 2012).

La figura con mayor continuidad y reconocimiento dentro del campo específico de los estudios sobre administración y políticas públicas en el país es, sin lugar a dudas, Oscar Oszlak, quien se desempeño durante 25 años como director de maestría en Administración Pública de la Universidad de Buenos Aires, en la Facultad de Ciencias Económicas. Entre sus principales obras podemos mencionar: La formación del Estado Argentino; Merecer la ciudad. Los pobres y el derecho al espacio urbano y la compilación de Teoría de la burocracia estatal, en la que aparece un estudio anterior escrito en forma conjunta con O'Donnell: "Estado y políticas estatales en América Latina: hacia una estrategia de investigación" aparecido originariamente como Documento del CEDES en 1976 y publicado posteriormente como artículo en varias revistas de la especialidad es la obra argentina más utilizada en los distintos capítulos que integran el libro Estado y Administración Pública. Críticas, enfoques y prácticas en la Argentina actual compilado por Guillermo Schweinheim en 2009. Este libro colectivo reúne las ponencias más destacadas de los cinco primeros Congresos Argentinos de Administración Pública organizados en forma conjunta por la Asociación Argentina de Estudios de la Administración Pública (AAEAP) y la Asociación de Administradores Gubernamentales.

La formación del Estado argentino se ha convertido, a lo largo de los años, en el libro de ciencia política con mayor cantidad de impresiones, presentado dos versiones del texto. En él Oszlak desarrolla claramente el enfoque "histórico-estructural" y su concepción de la estatidad como el conjunto de atributos que hacen a la construcción de cada forma estatal sin perder sus particularidades. En esta visión, se articulan las tradiciones weberiana y marxista para comprender la dinámica estatal; es por ello que la obra no solo ha constituido una pieza de ciencia política, sino que traza un puente con la historia y la economía, de ahí su fuerte reconocimiento y difusión durante estas décadas. 
Con el advenimiento de la democracia se fueron creando diferentes grupos de investigación a lo largo del país; nuevas carreras de ciencia política, relaciones internacionales y administración pública dieron terreno fértil a la consolidación de este campo de estudios, donde el posgrado, como ya hemos mencionado, ha tenido un rol central. Cabe destacar que las asociaciones de ciencias sociales como la Sociedad Argentina de Análisis Político (SAAP) y la Asociación Argentina de Estudios de la Administración Pública (AAEAP) tuvieron también un rol destacado en la construcción de redes y en el intercambio de trabajos, principalmente a partir de sus eventos, congresos y publicaciones. Entre los iniciadores de los estudios sobre la administración pública cabe mencionar a Pedro Andrieu, quien hace más de 40 años constituyó la primera cátedra de "Administración Pública y Empresas Públicas" de la Facultad de Ciencias Económicas de la UBA. Durante las últimas dos décadas podemos mencionar a Fabián Repetto, autor de Gestión Pública y desarrollo social en los noventa. Las transformaciones de Argentina y Chile. Otros trabajos destacados son La reforma managerialista de Alejandro Estévez quien también compiló Estado, Sociedad y Cultura Democrática en la Reforma del Estado Argentino; e Introducción a la Administración Pública Argentina: Nación, Provincia y Municipios junto a Horacia Cao y Gustavo Blutman.

En la Facultad de Ciencias Sociales de la Universidad de Buenos Aires no podemos dejar de mencionar a Mabel Thwaites Rey quien ha escrito las obras Alas rotas. La política de privatización y quiebre de Aerolíneas Argentinas y La autonomía como búsqueda, el Estado como contradicción; y las compilaciones junto a Andrea López, de Entre tecnócratas globalizados y políticos clientelistas. Derrotero del ajuste neoliberal argentina; este equipo de trabajo ha desarrollado a lo largo de estos años la tradición neomarxista sobre el Estado en el país, siendo fuertemente reconocido dentro de los cultores de esta perspectiva teórica.

Dentro de otros grupos de investigación en administración pública, en la Universidad de Buenos Aires, debemos mencionar el Programa de Estudios sobre Sector Público y Reforma del Estado, dirigido por Dora Orlansky, en el Instituto Gino Germani; y el Centro de Investigaciones en Administración Pública (CIAP) en la Facultad de Ciencias Económicas, dirigido por Isidoro Feldman, ambos sedes de proyectos de investigación UBACYT, que desarrollan actividades de investigación en forma regular desde el año 1994 y 2001, respectivamente. El CIAP realizó junto a la Asociación Argentina de Estudios de la Administración Pública (AAEAP) durante 2017 una investigación ("Consulta sobre normativa y textos de autores argentinos") para relevar los textos más destacados de la disciplina en el país producidos durante la última década en base a encuestas personas vinculada al área (expertos, funcionarios, académicos e investigadores), destacándose ante todo la ya mencionada figura de Oscar Oszlak. Esto permite construir una cartografía de publicaciones, pero ante todo analizar la compleja construcción del prestigio y sus implicancias simbólicas.
El desarrollo de los estudios sobre administración y políticas públicas en la Argentina

Nelson Dionel Cardozo 
Dossier América Latina: desarrollo y balance de la ciencia política
En la Universidad Nacional de Rosario fue creado en 1997 por docentes de la Facultad de Ciencia Política y Relaciones Internacionales el Grupo Política y Gestión. Surgido bajo los lineamientos del Programa Universitario de Administración Pública, esta institución se radicó como Centro de Estudios de la Facultad de Ciencia Política y Relaciones Internacionales. Dirigido originariamente por Cristina Díaz sus miembros son docentes e investigadores con reconocida trayectoria, particularmente en el ámbito local destacándose Rita Grandinetti y Patricia Nari. Las actividades incluyen la investigación y la participación en múltiples proyectos con organizaciones del ámbito estatal y comunitario, los cuales han permitido desarrollar una valiosa capacidad de trabajo interdisciplinario. Hasta la fecha este grupo de investigación ha realizado dos Simposios sobre Administración Pública.

Dentro de la Facultad Latinoamericana de Ciencias Sociales - Sede Buenos Aires (FLACSO) se viene desarrollando el Programa de Estado y Políticas Públicas bajo la dirección de Daniel García Delgado; acompañándolo un equipo de investigadores entre los que podemos mencionar a Jorge Tirenni, Sergio Del Piero, Alejandro Casalis, Salvador Tiranti, Cristina Ruiz del Ferrier, Agustina Gradin, María Racovschik y Cynthia Ferrari Mango. A lo largo de estos años García Delgado ha publicado tres obras vinculadas a esta problemática, Estado \& Sociedad, Estado-Nación y globalización y posteriormente Globalización y crisis del Estado-Nación. Esta área viene publicando desde hace unos años la revista Estado y Políticas Públicas. Hasta la fecha el programa ha realizado dos Congresos Nacionales de Estado y Políticas Públicas.

En la Universidad Nacional de Lanús se destaca la figura de Carlos María Vilas, quien ha sido mencionado en la edición especial por el $40^{\circ}$ aniversario de la prestigiosa revista francesa "Le Nouvel Observateur" como uno de los intelectuales más influyentes de la región. Uno de los aportes que viene desarrollando esta institución es la publicación de la revista "Perspectivas de Políticas Públicas".

Dentro de los estudios sobre desarrollo local podemos situar a Pedro Pírez, Alejandro Villar, Sergio Ilari y Daniel Cravacuore, director de la Unidad de Fortalecimiento de los Gobiernos Locales de la Universidad Nacional de Quilmes; y Gustavo Badía anteriormente en el ICO de la Universidad Nacional de General Sarmiento y a partir de 2010 en la Universidad Nacional de San Martín. En la Universidad Nacional de La Matanza ha venido desarrollando su programa de investigación Gloria Mendicoa con estudios fuertemente anclados en la realidad de ese partido y sus aledaños. En la Universidad Nacional de Córdoba desde hace años se destacan Claudio Tecco y Silvana López orientados también hacia los estudios sobre políticas locales.

Entre la producción realizada en la Universidad Católica de Córdoba relativa a la temática podemos mencionar Diseño y gestión de políticas públicas. Hacia un modelo relacional de Emilio Graglia, Políticas públicas y largo plazo. El programa social mexicano PROGRESA de Marcos Roggero y Sobre llovido mojado de Silvia Fontana. En cuanto a la problemática de la comunicación gu- 
bernamental orientado hacia las políticas públicas y las decisiones de gobierno cabe mencionar La construcción del consenso. Gestión de la comunicación gubernamental de Luciano Elizalde, Damián Fernández Pedemonte y Mario Riorda. Entre los egresados de la Universidad Nacional de Cuyo podemos mencionar a los destacados investigadores Aldo Isuani, Eduardo Bustelo y Emilio Tenti Fanfani, quiénes a su vez ejercieron importantes cargos en la gestión pública en diferentes gobiernos desde la democratización.

Uno de los campos que se ha venido desarrollando en los últimos años es el de las políticas de seguridad pública; temática de alguna forma "abandonada" por la ciencia política desde la democratización y retomada a partir de la denominada "crisis del modelo policial". Este conjunto de problemáticas es fuertemente interdisciplinario compartiendo espacios con la criminología, el derecho penal, la psicología y la sociología del delito. Dentro de la ciencia política la figura más destacada es Marcelo Sain, quién, además de investigar y poseer una importante producción académica, ha ocupado varios cargos de gestión en el área. Entre sus principales obras podemos destacar: El leviatán azul. Policía y política en la Argentina; La reforma policial en América Latina. Una mirada crítica desde el progresismo; Por qué preferimos no ver la inseguridad (aunque digamos lo contrario).

Dos trabajos merecen ser mencionados, por un lado, Lecturas sobre el Estado y las políticas públicas: Retomando el debate de ayer para fortalecer el actual, compilado por Carlos Acuña, el que sintetiza gran parte de la trayectoria mundial y regional sobre la problemática del Estado y las políticas públicas; y Estado y Administración Pública: Críticas, enfoques y prácticas en la Argentina actual, compilado con Guillermo Schweinheim, obra que reúne algunas ponencias de los Congresos Argentinos de Administración Pública organizados por la AAEAP, principal evento en el país específico sobre esta temática. En esta institución cabe mencionarse los aportes sustantivos para su creación y continuidad de Alberto Bonifacio y del ya mencionado Guillermo Schweinheim. Fuera del ámbito universitario, la Dirección de Investigaciones del Instituto Nacional de la Administración Pública realiza y promueve estudios e investigaciones para contribuir al desarrollo del conocimiento sobre la administración pública y el Estado. Recientemente el INAP ha emprendido dos publicaciones periódicas: por un lado, la revista de divulgación "Apuntes para la modernización del Estado" y, "Estado Abierto", esta última bajo la dirección de Oscar Oszlak.

\section{La nunca acabada construcción del prestigio}

En el campo académico y científico el prestigio es uno de los elementos distintivos, el mismo se construye a lo largo del tiempo, dentro de la carrera académica de investigadores, grupos e instituciones. Una compleja trama de relaciones sociales estructura este "bien positivo" que tiene hondas raíces en
El desarrollo de los estudios sobre administración y políticas públicas en la Argentina

Nelson Dionel Cardozo 
Dossier América Latina: desarrollo y balance de la ciencia política la cultura occidental. Viejos poetas y filósofos, teólogos y pensadores medievales, integrantes de las universidades y academias nacionales se han caracterizado por privilegiar este elemento frente a otros que hacen a los sistemas de desigualdad presente entre los hombres como son el dinero y el poder; existiendo desde luego fuertes vasos comunicantes entre los tres elementos (Bulcourf 2017).

Con la institucionalización de los sistemas universitarios y centros de investigación con posterioridad a la Segunda II se fueron estableciendo las bases actuales y los elementos que hacen al prestigio de los científicos centrados principalmente en la relevancia de sus descubrimientos y aportes. Por lo general, es un elemento construido intersubjetivamente dentro de la propia comunidad, y muchas veces exteriorizándose hacia la sociedad en un reconocimiento mayor, muchas veces controversial y articulado con la notoriedad y la fama, agudizado por los medios masivos de comunicación. Salir en forma reiterada en la televisión o escribir en el periódico proyectan a los académicos más allá de su ámbito. Esto también ha dado lugar a la aparición, hacia fines del siglo XIX, de lo que se ha denominado el "intelectual moderno", aquella figura destacada y prestigiosa cuyas ideas orientan el accionar público y generan efectos importantes en la opinión pública. Es ahí donde éste actúa como un puente entre ámbitos cerrados del campo académico y se posiciona cercano a los políticos, generalmente destacándose su aspecto crítico.

Por otro lado, en ciertas áreas dentro de disciplinas como la economía, la sociología o la ciencia política, existen diferencias importantes en la forma de producir y aplicar el conocimiento. Por ejemplo, no es lo mismo dedicarse a la filosofía política o la historia del pensamiento que al campo de la administración y las políticas públicas que estamos tratando de abordar en este trabajo. Por lo general, en América Latina se ha ido imponiendo lo que se denomina el "modelo liberal" del académico, el que es evaluado en forma periódica principalmente por los elementos señalados, generando fuertes discusiones dentro de la comunidad científicas que se articulan con la propia concepción que tenemos de la ciencia y su utilidad social (Bulcourf 2017).

El campo específico de los estudios sobre Estado, administración y políticas públicas estructura el prestigio en la confluencia de los elementos polares: por un lado, los indicadores tradicionales antes mencionados, y por el otro la aplicación y la participación en diferentes escenarios de la esfera pública y el ámbito de la consultoría. Por esta razón, no es necesariamente equivalente al que puede encontrarse en otras áreas de la ciencia política, como pueden ser la política comparada y el estudio de las instituciones. A esto debe añadirse algo que es común a todo el campo de las ciencias humanas y sociales, que es la perspectiva teórica y metodológica adoptada, lo que también se vincula a la ya mencionada concepción de la ciencia y como ésta debe ser construida y validada. Por esta razón, los criterios de una persona que adopta una posición clasista orientada por los trabajos de Marx y sus seguidores puede diferir de quien utiliza la teoría de la acción racional o el neoinstitucionalismo; así tam- 
bién si prefiere enfoques de corte cualitativo o cuantitativo. Esto ha llevado muchas veces a que la comunidad científica se halle en compartimientos estancos, con poca comunicación entre ellos, lo que muy bien ha estudiado en la ciencia política Gabriel Almond y su planteo de las "mesas separadas" basado en el cruce entre un aspecto ideológico-teórico y otro metodológico (Almond 1999). Otro elemento a tener en cuenta es la pertenencia institucional y el país en cuestión; más allá de la posición teórica y metodológica, la política científica que es seguida por los Estados condiciona y moldea la producción académica; los criterios de evaluación de revistas como también la asignación de presupuestos de investigación y de becarios poseen orientaciones muy diferentes. También el clivaje entre universidades públicas y privadas, laicas o confesionales, y populares o elitistas, configura la concepción que tengamos sobre los criterios a establecerse. Esto nos demuestra que las variables que inciden son demasiadas y su forma de ponderación dará resultados muy diferentes; no tener en cuenta estos criterios y someterlos a la reflexión crítica o bien obedece a una idea muy inocente de la comunidad científica o bien una forma indirecta de manipulación bajo una supuesta "objetividad".

En el caso argentino que estamos abordando se han destacado principalmente dos autores que hemos mencionado: Oscar Oszlak y Guillermo O'Donnell. Ellos han sabido lograr una amplia aceptación por parte de los miembros de la comunidad académica y científica y de los propios expertos en gestión pública. El caso de $\mathrm{O}^{\prime}$ Donnell se fundamenta principalmente en su lugar general como politólogo y su inserción internacional como así también en la construcción de conceptos específicos y su posterior aceptación y discusión por parte de la comunidad académica. Por esta razón es su visión sobre el Estado el eje que más pondera en esta construcción (Bulcourf 2015; Cardozo 2012). La participación conjunta de ambos en el CEDES es un elemento central, dado que el texto más citado ha sido hasta la fecha Estado y políticas estatales en América Latina: hacia una estrategia de investigación, dado que apareció originalmente en 1976 y sirvió de orientación a muchos trabajos sobre el proceso de políticas públicas y el rol de los actores dentro de éste. El caso de Oszlak combina los dos elementos centrales para la construcción del prestigio en el área. Ha sido tanto funcionario público, consultor internacional, investigador superior del CONICET y creador y director de la maestría en Administración Pública de la UBA y profesor de posgrado en la mayoría de los programas mencionados. A esto hay que sumarle su carácter de profesor titular en la temática a partir de la creación de la carrera de ciencia política en la mencionada universidad, lo que le ha permitido un reconocimiento desde los propios estudiantes de grado. Su libro La formación del Estado argentino se ha transformado en un texto insignia dentro y fuera de la ciencia política. La continuidad en el área es otro elemento sustantivo en este caso, dado que ha permanecido durante décadas como uno de los referentes centrales en América Latina, formando parte del minoritario y selecto grupo de miembros del Consejo Científico del CLAD y actualmente uno de los especialista más
El desarrollo de los estudios sobre administración y políticas públicas en la Argentina

Nelson Dionel Cardozo 
Dossier América Latina: desarrollo y balance de la ciencia política renombrados en la problemática del "gobierno abierto" y quién ha propuesto una nueva concepción al respecto, ampliando esta visión a la de Estado abierto. El mencionado estudio realizado por el CIAP y la AAEAP no ha hecho más que corroborar esta afirmación (Pando 2017).

\section{Conclusiones: un balance provisorio del campo y su institucionalización}

En este artículo hemos realizado algunos avances sobre trabajos previos sobre el desarrollo de la administración pública como campo disciplinar a partir del estudio de los programas de grado y posgrado, teniendo en cuenta su desarrollo histórico. Lo que surge de este análisis es que se genera como orientación o área de la ciencia política, lo cual se evidencia en la creación de la primer carrera de grado con esta denominación durante el peronismo en la Universidad Nacional de Cuyo. La carrera de Ciencia Política y Administración Pública fue el primer programa destinado a la formación de funcionarios como parte del proyecto de posguerra de ampliación de las funciones del Estado Benefactor, al mismo tiempo que una faceta de formación de una nueva clase dirigente. Como puede advertirse, hay una gran diferencia con los países centrales, en los cuales aparece como una "ciencia de las políticas", destinada a generar conocimiento empírico para intervenir en la calidad de las políticas públicas participando centralmente en la planificación.

Un hecho fundamental para la consolidación del campo institucionalizado es la Educación Superior, donde la acreditación de la maestría exige que se produzca una tesis, por lo que instauró exigencias de producción de trabajos de investigación para obtener el título a los maestrandos, desvinculando aún más las maestrías de la gestión. No obstante ello, la Maestría en Administración Pública de la UBA, que es el programa de formación de posgrado más antiguo -junto con el de la Universidad Di Tella-, se presenta de manera ambigua, dado que propone formación para los puestos de conducción al mismo tiempo que competencias para la docencia y la investigación. Sus directivos, no obstante ello, resaltan la inserción de los graduados en posiciones en el aparato estatal como un logro del programa, que retroalimenta el interés de funcionarios de carrera por ingresar a la maestría. Podemos esgrimir que hubo un crecimiento sostenido de los programas de posgrado, sobre todo desde finales de los años 90, al calor de las reformas de segunda generación, que tenía como eje fundamental el fortalecimiento de las capacidades estatales y la reforma interna de la administración pública. En este orden de ideas, se buscará la adecuación de las agencias gubernamentales hacia la atención del ciudadano, con énfasis en un modelo más flexible, ligado a las concepciones gerencialistas; como así también aparecerá como un eje la "calidad institucional" en el desarrollo se alcanzará a partir del cuidado de la calidad de las reformas, la eliminación de prácticas de corrupción, y la mejora de las potestades 
regulatorias de los gobiernos. Es durante esta etapa, que se van creando en las nuevas universidades del Conurbano tres carreras claramente orientadas al formar profesionales que se desempeñen en la gestión de políticas públicas. La Universidad del Comahue y la Universidad Autónoma de Entre Ríos crean sus respectivas carreras en Viedma y Paraná. La UADE es la primera carrera de administración pública dictada en una universidad privada a partir del año 2008, seguida en el 2014 por la UMET. En el siguiente cuadro se condensan las diferentes etapas que podemos ver del desarrollo de la formación en administración pública en la Argentina.

\begin{tabular}{|c|c|c|}
\hline Etapa & Características & Tipo de programa principal \\
\hline $1952-1983$ & $\begin{array}{l}\text { Formación de burócratas } \\
\text { especializados. } \\
\text { Peronismo } \\
\text { Experiencia embrionaria } \\
\text { y aislada } \\
\text { Discontinuidad institucional }\end{array}$ & $\begin{array}{l}\text { Grado. Carrera de Ciencia Política } \\
\text { y Administración Pública de la } \\
\text { UNCUYO. } \\
\text { Lic. en Adm. Pública de la } \\
\text { Universidad de El Salvador }\end{array}$ \\
\hline $1983-1990$ & $\begin{array}{l}\text { Democratización } \\
\text { Preocupación por la función } \\
\text { pública } \\
\text { Articulación entre organismos } \\
\text { y universidad }\end{array}$ & $\begin{array}{l}\text { Posgrado. } \\
\text { Creación de la maestría en Políticas } \\
\text { Públicas del Instituto Di Tella } \\
\text { y maestría en Administración } \\
\text { Pública de la UBA }\end{array}$ \\
\hline $1990-1996$ & $\begin{array}{l}\text { Reforma del Estado } \\
\text { Acreditación del Posgrado } \\
\text { y requisito de tesis }\end{array}$ & Nulo crecimiento de los programas \\
\hline 1996-Actualidad & $\begin{array}{l}\text { Nueva reforma del Estado } \\
\text { Crisis del modelo Neoliberal }\end{array}$ & $\begin{array}{l}\text { Creación de programas de grado } \\
\text { orientados a la gestión pública } \\
\text { Surgimiento de programas de grado } \\
\text { en universidades privadas }\end{array}$ \\
\hline
\end{tabular}

Fuente: Elaboración propia.

Esta periodización es heredera de los estudios previos que se han realizado sobre aspectos más generales de la conformación del campo de la ciencia política, donde vemos que hay algunas tendencias que no pueden ser ignoradas en relación a los programas de políticas públicas. La primera afirmación que podemos realizar es que la creación de programas de grado es una experiencia reciente, en facultades pequeñas, por lo que son tramos que abarcan un número reducido de alumnos. Ello no debe opacar que el posgrado también es una experiencia acotada, pero el peso de los actores es lo que le da más relevancia. Si vemos los autores de las tesis entregadas de cada una de las maestrías, podemos advertir que por sí mismo, el nivel de posgrado tiene una gravitación mayor en términos cualitativos por la relevancia que tienen los graduados tanto en la academia como en la gestión pública. Los principales referentes del área
El desarrollo de los estudios sobre administración y políticas públicas en la Argentina

Nelson Dionel Cardozo

\section{Cuadro 5.}

Etapas la formación universitaria en administración pública 


\begin{tabular}{|c|c|c|c|c|}
\hline \multirow[t]{4}{*}{$\begin{array}{r}\text { Dossier } \\
\text { América Latina: } \\
\text { desarrollo y balance } \\
\text { de la ciencia política }\end{array}$} & \multicolumn{4}{|c|}{$\begin{array}{l}\text { en nuestro país que se han formado en Argentina han transitado las maestrías } \\
\text { del área. En el siguiente cuadro podemos ver la sumatoria total de programas } \\
\text { de grado y posgrado según tipo de gestión: }\end{array}$} \\
\hline & Nivel Gestión & Pública & Privada & TOTAL \\
\hline & Doctorado & 2 & - & 2 \\
\hline & Maestría & 10 & 6 & 16 \\
\hline $\begin{array}{r}\text { Cuadro } 6 . \\
\text { Tipo de programa }\end{array}$ & Grado & 6 & 2 & 8 \\
\hline $\begin{array}{l}\text { en administración pública } \\
\text { según tipo de gestión }\end{array}$ & TOTAL & 18 & 8 & 26 \\
\hline
\end{tabular}

Fuente: elaboración propia con base en datos de la CONEAU.

Lo primero que observamos del análisis es que la administración pública se halla más desarrollada tanto al nivel de posgrado como de grado en las universidades públicas. De las 15 maestrías 10 están en universidades públicas y 6 en privadas. La maestría más importante, en términos históricos y con mayor número de tesis entregadas, la de la Universidad de Buenos Aires, demuestra que en la formación en el área la densidad de los centros públicos es indiscutida. Lo mismo puede decirse del nivel de grado, en donde hasta el año 2008 la licenciatura en administración pública era monopolio estatal, hasta la creación de la de Gobierno y Administración Pública en la UADE, y desde el 2014 con la creación de la licenciatura en Gobierno y Políticas Públicas de la UMET. Desde el año 2010 encontramos que ha nacido el doctorado como trayecto formativo en el área, a partir de la creación del programa en la UNC, seguido luego por la UNL.

Como reflexiones finales, podemos decir que la administración y políticas públicas se han desenvuelto en la Argentina a modo de un campo del saber que se encuentra asentado mayormente en el posgrado con una impronta interdisciplinar. Sin menoscabo de ello, estamos asistiendo a una nueva fase de consolidación de esta área, con la creación de nuevas carreras de grado con un perfil muy diferente al de las maestrías, con una mirada más profesionalista que intenta apartarse del peso de la ciencia política con su impronta fuertemente académica. Al mismo tiempo, vemos que a raíz de la política de evaluación y acreditación universitaria seguida por la CONEAU, el posgrado es un trayecto netamente académico, mientras que los ciclos de licenciatura proponen una inserción en la gestión más concreta, motivo por el cual es esperable que con el correr de los años haya más profesionales con título de grado desempeñándose en las burocracias, sin por ello pensar que el posgrado debiera quedar confinado a la investigación y la academia.

Asimismo podemos sostener que a partir de la democratización se han consolidado diferentes grupos de investigación, muchos de ellos vinculados 
a las experiencias de grado y posgrado analizadas. Dentro de la agenda temática, el propio crecimiento del campo nos lleva a una marcada pluralización y especialización, siempre vinculada en parte a los propios problemas políticos y sociales que se van generando y promueven tanto la iniciativa de nuevas problemáticas como así del conocimiento experto para la propia toma de decisiones, aunque no hay un correlato directo. El campo es también muy fértil en el interior del país, dado que muchas de las carreras de grado y los grupos de investigación están por fuera de la región metropolitana; en muchos casos los estudiantes de grado y posgrado ven en la propia administración pública un posible ámbito del ejercicio laboral.

Por otro lado, hemos intentado comenzar a plantear el complejo y controversial problema de la construcción del prestigio, sin caer en reduccionismos y exponiendo el carácter político que también está presente en el campo académico, algo que muchas veces los científicos se rehúsan a admitir. Dentro de la comunidad científica se articulan relaciones de poder con sus características propias, teniendo una enorme consecuencia en la asignación también de los recursos materiales. En lo que respecta al caso argentino hemos nombrado a dos de los académicos que han generado el mayor consenso durante las últimas décadas en ser los expertos más reconocidos, Oscar Oszlak y Guillermo O’Donnell, en donde las biografías intelectuales de cada uno, como los momentos por los que han atravesado, sin lugar a dudas generan cierta "singularidad" que es muy difícil de expresar, aunque todos los estudios realizados confirman esta idea.

Este trabajo es ante todo introductorio, ya que hay muy pocas investigaciones específicas al respecto en la Argentina, por lo tanto es más que nada un llamado a su continuidad y evaluación crítica, para seguir indagando sobre el Estado, la administración y las políticas públicas, en donde el conocimiento y la experiencia se conjugan a veces sin saberlo con los propios laberintos del poder que intentan abordar.

\section{Bibliografía}

Alford R., Friedland R. (1991), Los poderes de la teoría, Manantial, Buenos Aires.

Almond G. (1999), Una disciplina segmentada. Escuelas y corrientes en ciencia política, México, Fondo de Cultura Económica.

Acuña C. (comp.) (2007), Lecturas sobre el Estado y las Políticas Públicas: Retomando el debate de ayer para fortalecer el actual, Buenos Aires, Jefatura de Gabinete de Ministros/ Proyecto de Modernización del Estado.

Agoff S. (2003), Algunos problemas acerca de la emergencia del campo disciplinario y la formación en administración pública en Argentina, trabajo presentado en el Congreso Latinoamericano de Educación Superior en el Siglo XXI, septiembre, San Luis.

Agoff S., Badía G., Fagundez P., Mansilla G. (2003), Emergencia del campo disciplinario y formación en administración pública: El caso de la licenciatura en administración pública
El desarrollo de los estudios sobre administración y políticas públicas en la Argentina

Nelson Dionel Cardozo 
Dossier América Latina: desarrollo y balance de la ciencia política de la Universidad de General Sarmiento, ponencia presentada en el II Congreso Argentino de Administración Pública, noviembre, Córdoba.

Andrieu P. (2002), Equilibrio entre la visión de los posgrados y las necesidades del Sector Público: Tensión entre coyuntura y prospectiva en la formación, exposición en el Seminario Nacional sobre Posgrados con Orientación en Políticas Públicas, Instituto Nacional de la Administración Pública, noviembre, Buenos Aires.

Andrieu P, Asencio M. (2006), Formación gerencial para el Sector Público. Algunas experiencias, en: Estado y Administración Pública en la Argentina, P. Andrieu (comp.), Facultad de Ciencias Económicas-UBA, Buenos Aires.

Bourdieu P. (2003), Campo de poder, campo intelectual, Cuadrata, Buenos Aires.

Bulcourf P. (2008a), Enseñar a comparar: algunos desafíos en la enseñanza de la política comparada en la Argentina, "Boletín de Política Comparada", no 1, pp. 35-46.

Bulcourf P. (2008b), Algunas reflexiones sobre la enseñanza de la ciencia política en la Argentina, "PostData", no 13, pp. 39-57.

Bulcourf P. (2015), Guillermo O'Donnell y el desarrollo de la ciencia política en América Latina, en: Figuras, historias y territorios. Cartógrafos contemporáneos de la indagación política en América Latina, I. Covarrubias (coord.), Cruz O, México.

Bulcourf P. (2017), Historia de la ciencia política en América Latina: entrevista con Pablo Bulcourf, "Realis", vol. 7, no 1 pp. 234-257, entrevista realizada por Marcelo Cigales.

Bulcourf P., Vazquez J. C. (2004), La ciencia política como profesión, "PostData", no 10, pp. 255-304.

Bulcourf P., Cardozo N. (2017), La Ciencia Política en América Latina: un análisis comparado de su desarrollo, en: La Ciencia Política sobre América Latina: docencia e investigación en perspectiva comparada, F. Freidenberg (ed.) FUNGLODE, Santo Domingo.

Bulcourf P., Dufour G., Cardozo N. (2013), Administración y políticas públicas en la Argentina: una revisión histórica, "Perspectiva sobre el Estado, las Políticas Públicas y la Gestión”, vol, 1, no 1, pp. 136-153.

Bulcourf P., Gutiérrez Márquez E., Cardozo N. (2014), El desarrollo de la ciencia política en Argentina, Brasil y México: construyendo una mirada comparada, "Anuario Latinoamericano - Ciencias Políticas y Relaciones Internacionales", vol. 1, pp. 155-184.

Bulcourf P, Gutiérrez Márquez E., Cardozo N. (2015), Historia y desarrollo de la ciencia política en América Latina: reflexiones sobre la constitución del campo de estudios, "Revista de Ciencia Política", vol. 35, no 1, pp. 179-199.

Cardozo N. (2012), Algunas reflexiones sobre Gillermo O'Donnell y su contribución a la teoría del Estado y los estudios sobre políticas públicas en América Latina, "Estudia Politicae", no 26, pp. 39-72.

Cardozo N., Bulcourf P. (2016), El desarrollo institucional de la administración y políticas públicas en Argentina. Un estudio de la enseñanza desde el proceso democratizador hasta nuestros días, "Estudios Políticos", no 49, pp. 216-238.

Guardamagna M. (2008), La Ciencia Política en Cuyo: el auge antes de la crisis, ponencia presentada en el VIII Congreso Nacional de Democracia, Rosario.

Guardamagna M. (2009), Elitismo e igualdad política en los orígenes de la Ciencia Política en Cuyo, ponencia presentada en el IX Congreso de Ciencia Política, Santa Fe. 
Isuani E. (1991), Bismarck o Keynes ¿quien es el culpable?: notas sobre la crisis de acumulación, en: El Estado de Bienestar: crisis de un paradigma,

E, Isuani, R. Lo Vuolo y E. Tenti, CIEPP/Miño Dávila, Buenos Aires.

Lasswell H. (1992), La orientación hacia las políticas, en: El Estudio de las Políticas Públicas, L. Aguillar Villanueva (ed.), Porrúa, México.

Manifiesto de Popayán (2014) Ciudad de Popayán, Colombia.

Oszlak O. (2000), El Posgrado en Administración Pública: una Maestría pionera, “Temas y Propuestas", vol. 18, no 9, pp. 78-95.

Oszlak O. (1997), La administración pública como área de investigación: la experiencia de Argentina, ponencia presentada en el II Congreso del CLAD sobre la Reforma del Estado y la Administración Pública, octubre, Isla de Margarita.

Oszlak O. (2002), La inserción e impacto de los egresados de los posgrados en el Sector Público, exposición en el Seminario Nacional sobre Posgrados con Orientación en Políticas Públicas, Instituto Nacional de la Administración Pública, noviembre, Buenos Aires.

Oszlak, O. (2007), Entrevista, "Cuestiones de Sociología”, no 4, pp. 187-210, entrevista realizada por Camou, A., Marcial, A., Soprano Manzo, G. y Flavio, G.

Oszlak, O. (2008), Entrevista, "PostData", no 13, pp. 245-253, entrevista realizada por el equipo de redacción de la revista.

Pando D. (2017), Entrevista, realizada por Pablo Bulcourf (sin publicar).

Pérez Sánchez M. (2005), Origen y desarrollo del análisis de políticas, en: Análisis de políticas públicas, M. Pérez Sánchez, Editorial Universidad de Granada, Granada.

Seró de Bottinelli Cr. (2001), La maestría en Administración Pública de la Universidad de Buenos Aires: contribuciones, paradojas y desafíos, ponencia presentada en el VI Congreso Internacional del CLAD sobre la Reforma del Estado y la Administración Pública, noviembre, Buenos Aires.

Shweinheim G. (comp.) (2010), Estado y Administración Pública: Críticas, enfoques y prácticas en la Argentina actual, Asociación de Estudios de Administración Pública, Buenos Aires.

Weber M. (1984), Economía y sociedad, Fondo de Cultura Económica, México
El desarrollo de los estudios sobre administración y políticas públicas en la Argentina

Nelson Dionel Cardozo 